\title{
O PRINCÍPIO DA LEGALIDADE EM TEMPOS DE PANDEMIA
}

\section{LEGALITY PRINCIPLE IN PANDEMIC TIMES}

\section{Vitor Galvão Fraga ${ }^{1}$ \\ Edilson Pereira Nobre Júnior ${ }^{2}$}

\section{RESUMO}

O presente artigo versa sobre o princípio da legalidade no contexto da crise sanitária causada pelo coronavírus em 2020. Especificamente, busca-se aqui questionar o senso comum de que a situação emergencial pode justificar mitigações à reserva de lei no âmbito do direito administrativo ordenador. Para trabalhar essa temática, começamos por uma análise da competência dos entes federados em matéria de saúde dentro no contexto do federalismo brasileiro. A partir daí, traçamos as características e implicações do princípio da legalidade administrativa para, num terceiro momento, analisar sua imperatividade no tocante aos atos normativos sancionatórios expedidos pelas Administrações estaduais e municipais. Concluímos, como não poderia deixar de ser, pela higidez do primado da legalidade e do Estado Constitucional de Direito mesmo diante das demandas urgentes da crise sanitária, expondo que o ordenamento jurídicodispõe de meios que podem acelerar o processo legislativo sem que se precise recorrer à flexibilização da legalidade.

Palavras-chave: Competência. COVID-19. Federalismo. Legalidade. Saúde.

\section{ABSTRACT}

The presente article is about the legality principle in the context of COVID-19's sanitary crisis in 2020. Specifically we aim to lay doubt over te common sense that the emergency situation can justify a mitigation on law's reserve in the realm of administrative law. In order to develop this subject, we start by analysing the competence of the federative entities on matter of health in the context of brazialian's federalism.From there we can draw the characteristic and implications of the legality principle, and then, in a third moment, analyse its imperativeness in

\footnotetext{
${ }^{1}$ Mestrando do Programa de Pós-Graduação em Direito da Faculdade de Direito do Recife - UFPE. Especialista em Direito Administrativo - UFPE. Especialista em Direito Constitucional - Faculdade CERS. Integrante do Grupo de Pesquisa "Desafios do Controle da Administração Pública Contemporânea". Advogado.

${ }^{2}$ Professor Titular da Faculdade de Direito do Recife - UFPE. Doutor em Direito Público. Líder do Grupo de Pesquisa "Desafios do Controle da Administração Pública Contemporânea". Desembargador do Tribunal Regional Federal da Quinta Região.
} 
the matter of sanctionary normative acts edited by the Administration of States and Municipalities. We come to the inevitable conclusion that the legality principle and the Constitutional State of Law stay unbended even facing the urgent demands of the sanitary crisis, exposing that the legal order has means to accelarate the legislative process without having to resort to legality's erosion.

Keywords:Competence.COVID-19.Health.Federalism.Legality.

"O princípio da legalidade exprime que a Administração deve sempre agir conforme as regras que lhe são aplicáveis." - Didier Truchet $\left(2017\right.$, p. 52) ${ }^{3}$

\section{INTRODUÇÃO}

O Direito, como sistema de ordenação de condutas, não se exaure nos confins dos seus textos normativos. Põe-se em movimento diante dos desafios da realidade, a qual nem sempre é previsível, muitas vezes cedendo diante de ocorrências extraordinárias.

Há pouco o clima de aparente tranquilidade global foi quebrantado de uma forma inesperada, mas não por explosões provocadas por armas atômicas, tal como se pressupunha em tempos de Guerra Fria, com relação à qual se temia que, por uma terceira vez, houvesse a conflagração de um conjunto numeroso de Estados, desta vez com risco de desaparição da humanidade.

Diversamente, pelo menos em gravidade, o desenvolvimento tecnológico - que implicou no encurtamento de fronteiras não somente virtual, mas físico -, fez com que um vírus, com a sua invisibilidade, pudesse percorrer os quase inteiramente a superfície da Terra, ocasionando uma pandemia capaz de atentar, caso não contida, contra a vida de milhões de pessoas.

O enfrentamento da situação requer atuação do Estado no sentido de envidar ações para que seja evitado os riscos da expansão da enfermidade, tal qual se tem no art. 196, caput, da Constituição Federal.

Tal sucede mediante a atuação primordial da função administrativa, à qual incumbe realizar materialmente as prestações materiais a cargo do Estado em favor dos cidadãos, sem excluir a imposição - assídua, aliás - de limitações à conduta destes ${ }^{4}$.

\footnotetext{
${ }^{3}$ Tradução própria do original: "Le príncipe de légalité exprime cetteévidence que l'Administration doit toujours agir conformémentauxrèglesquis'appliquent à ele."

${ }^{4}$ A respeito de uma ideia de função administrativa, não se afigura equivocado, antes recomendável, evocar ensinamento de Marcelo Caetano, ainda portador de uma boa dosagem de atualidade, quando, em buscando
} 
Daí - importante não esquecer - que tal há que se desenvolver sob o pálio do Estado constitucional de Direito, o qual não suspende em épocas de crise.

Por isso, há que se observar dois pontos, a nosso ver interligados em face de peculiaridades do nosso sistema jurídico. O primeiro é o de que tal atividade há que se realizar com base no primado da legalidade, sendo a lei uma das mais importantes fontes jurídicas a orientar o legislador, bem como a convivência social. O outro é o de que a questão da legalidade há que ser vista de conformidade com a consideração de que o Estado brasileiro adotou a forma federal e, portanto, faz-se preciso perquirir a titularidade de competência legislativa, bem como a utilidade do seu desempenho pelos vários entes políticos.

Numa ordem inversão, principiaremos pela análise da competência federativa em sede de saúde.

\section{COMPETÊNCIA FEDERATIVA SOBRE SAÚDE}

O federalismo nasce nos Estados Unidos em $1787^{5}$ e, em sede constitucional, no Brasil, com a Constituição republicana de $1891^{6}$. Todas as constituições brasileiras posteriores mantiveram esse modelo de organização do Estado. No Federalismo, questão central e inescapável é a técnica de distribuição das competências, sede onde reside seus maiores debates.

A exemplo da Constituição norte-americana, a constituição de nossa primeira república privilegiava um federalismo dual, com competências catalogadas para os entes da federação de maneira estanque e precisa, sem atribuições compartilhadas, com base no que Karl Loewenstein chama de princípio da enumeração (Enumerationsprinzip $)^{7}$; nesse modelo, há uma espécie de

definir a Administração Pública em sentido orgânico, cogita de "um sistema de órgãos hierarquizados ou coordenados a que está atribuída a promoção e realização dos interesses colectivos por iniciativa própria, para a execução de preceitos jurídicos ou por imposição do bem comum, e utilizando todas as técnicas adequadas à obtenção dos resultados visados" (1990, p. 15).

${ }^{5}$ Os Estados Unidos foram o primeiro Estado propriamente federativo, no sentido técnico de federação, em que Estados antes soberanos, buscando coerência e homogeneidade, renunciam em favor do poder federal a maior e melhor parte de suas prerrogativas por meio não de um mero pacto, mas de uma Constituição Federal que institua poderes legislativo, executivo e judiciário a se estenderem sobre os interesses e negócios de cada Estado federado. Nesse modelo federativo os Estados Unidos foram pioneiros, apesar de antecedidos por uniões mais ou menos coesas de Estados soberanos, tal qual a Confederação Suíça e mesmo a primitiva organização das cidades-estados na Grécia Antiga. (CAVALCANTI, 1900).

${ }^{6}$ A primeira constituição brasileira que adota o federalismo como forma de Estado é a Constituição Republicana de 1891. Contudo, a federação já existia desde o ano anterior quando foi fundada pelo Decreto $\mathrm{n}^{\circ} 1 / 1890$ do Governo Provisório, cujo art. $1^{\circ}$ diz: "Fica proclamada provisoriamente e decretada como a forma de governo da Nação brasileira - a República Federativa.”. Disponível em

$<$ http://www.planalto.gov.br/ccivil_03/decreto/1851-

1899/D0001.htm\#: :text=das\%20autoridades\%20constitu\%C3\%ADdas.-,

Art.,livremente\%20expressado\%20pelo\%20sufr\%C3\%A1 gio\%20popular.> Acesso em 30 de junho de 2020

${ }^{7}$ Sobre o princípio da enumeração, no contexto da Constituição Estadunidense, diz Loewenstein (1959, p. 75) que “ (...) expressa inequivocamente que a Federação só pode exercer os poderes que lhe foram expressamente 
sistema de soma zero no qual as competências de cada ente são mutuamente excludentes, aquilo que cabe a um não pode, por inferência lógica, ser atribuído a outro. Esse dualismo esteve muito presente nos séculos XVIII e XIX por todos os estados que adotavam o modelo federal, até que no século XX atingiu seu declínio a partir do fortalecimento do Estado de bem-estar social.

O Estado social, fincado na ideia de justiça social, passou a consagrardireitos antes inexistentes nas ordens constitucionais, como o direito à saúde e à educação, concretizáveis por meio de políticas públicas a demandar uma intensa atividade prestacional com o desiderato de transformar a realidade econômica e social (AGRA, 2019, p. 174). Na promoção do bem-estar coletivo não faz mais sentido falar-se em um dualismo na repartição de competências, pois a promoção dessas políticas gera custos que são mais bem geridos de forma conjunta pelos entes da federação em soma de forças.

O modelo clássico de federalismo é inimigo do gasto público em grande escala, a fragmentação da autoridade contribui para um padrão de desenvolvimento de políticas a nível subnacional, que não só aumenta os níveis de desigualdade regional como diminui a magnitude da expansão da mudança social a nível nacional; um alto grau de centralização facilita o crescimento dos gastos públicos (CAMERON, 1978, p. 1253).Castles e McKinlay (1979, p. 104) chegam a afirmar, com base em estudo realizado no fim da década de 1970, que “(...) a significância de estruturas políticas descentralizadas como impeditivos a intervenções ativas de bem-estar socialé marcadamente maior que a influência negativa da dominância política de direita (...)".Quando as instituições da federação compartilham competência sobe políticas sociais esse problema é superado, evidenciando-se uma verdadeira dependência de trajetória (path dependence) entre o federalismo e o desenvolvimento de novos sistemas de proteção social (OBINGER; CASTLES; LEIBFRIED, 2005, p. 39).

O paradigma atual desse novo modelo de federalismo, chamado cooperativo, é a Lei Fundamental da República Federal da Alemanha de $1949^{8}$, que divide a repartição de

designados pela constituição, e que aos Estados ficam reservados todos os que não sejam atribuídos à União e não lhes sejam expressamente proibidos de exercer. Portanto, a Federação embasa suas competências em duas fontes, uma positiva de delegação expressa e outra negativa derivada da circunstância de que certas competências são proibidas aos Estados, o que indiretamente significa que são devidas à União, desde que não sejam sobre coisas, como direitos fundamentais, que estão completamente de fora do poder estatal" Tradução livredo original “(...) istunzweideutig zum Ausdruckgebracht, daß der BundnursolcheZuständigkeiten in Anspruchnehmendarf, die ihmausdrücklich von der Verfassungzugewiesensind, unddaßdenStaatenaile anderenverbleibenaußerden der Union zugewiesenenunddenen, derenAusübungihnen von der Verfassung ausdrücklichverbotenist. Der Bund leitet also seine Züstandigkeiten aus zwei Quellen ab, einmal positiv aus der ausdrücklichen Delegation, zum anderen negativ daraus, daß gewisse Kompetenzen den Staaten entzogen sind, womit indirekt zum Ausdruck gebracht wird, daß sie der Union zustehen, vorausgesetzt, es handelt sich nicht um Dinge, die, wie die Grundrechte, der staatlichen Herrschaftsgewalt überhaupt entzogen sind.".

${ }^{8}$ Registre-se que já a Constituição Austríaca de 1920 quebrou a ideia de exclusivismo das competências legislativas, tendo previsto em seu art. 12 para algumas matérias (como organização administrativa, construção civil, assistência social, etc.) que a competência da Federação (Bundessache)seria para leis principiológicas 
competências em dois seguimentos: a competência exclusiva da Federação (Bundestaat) e uma competência concorrente - predominante - entre a Federação e os Estados (Länder), que se exerce segundo os critérios estabelecidos pela Constituição. Esse modelo de federalismo cooperativo é presente ao longo de todo o texto da nossa Constituição Federal de $1988^{9}$, e de forma específica nos seus arts. 23 (competências administrativas comuns) e 24 (competências legislativas concorrentes). Trata-se, de um federalismo de participação, em que a responsabilidade sobre determinadas matérias, tanto administrativa quanto legislativa, é compartilhada entre os diversos entes.

O art. 196 da Constituição Federal de 1988 é lapidar e carregado de significado em seus termos. Ao dizer que a saúde é direito de todos e dever do Estado, indica que compreende uma dimensão individual e outra coletiva, que, para além de um direito público subjetivo, configura um dever fundamental de prestação para as três esferas federativas (União, Distrito Federal e Municípios). O art. 196, portanto, espelha a competência material prevista no art. 23, II, que se detalhe de forma mais específica com a instituição do SUS pelos arts. 197, 198 e 200.

As competências (materiais ou executivas) comuns do art. 23, nas quais se inclui "cuidar da saúde", se embasa na ideia de cooperação propriamente dita, isto é, a tomada de decisão conjunta em co-exercício de competência. Não há, nas competências comuns, qualquer supremacia de uma esfera sobre a outra (a competência tem a mesma medida para todos), sendo também comuns as responsabilidades, pressupondo uma estreita interdependência dentro de determinada matéria de interesse comum, o qual "viabiliza a existência de um mecanismo unitário de decisão, no qual participam todos os integrantes da Federação" (BERCOVICI, 2002, p. 16 - 17), apesar da execução ser possível de ser realizada separadamente.

O constituinte, por meio das competências comuns, obriga a combinação de esforços de todos os entes federativos para a defesa da saúde, caracterizando um verdadeiro dever de ação do qual nenhum dos entes pode se desincumbir (MENDES; BRANCO, 2017, p. 876). Não há, portanto, possibilidade de delegação ou transferência da competência comum, pois cabe ela a

(Gesetzgebungüber die Grundsätze) enquanto a competência dos Estados (Landessache) seria para editar leis de aplicação (Ausführungsgesetzen); contudo, isso não tinha o condão de afastar o caráter bastante centralista da Constituição, a qual previa que toda legislação estadual deveria ser submetida ao respectivo ministério federal de acordo com seu tema para que em oito semanas pudesse o Governo Federal avaliar qualquer ameaça a interesses federais e opor veto, o qual só poderia ser superado por quórum qualificado da Assembleia estadual (art. 98).

${ }^{9}$ Note-se, porém, que a Constituição de 1934 foi pioneira em nosso país ao prever competências materiais “concorrentes" entre União e Estados em seu art. 10 para "I - velar na guarda da Constituição e das leis; II cuidar da saúde e assistência públicas; III - proteger as belezas naturais e os monumentos de valor histórico ou artístico, podendo impedir a evasão de obras de arte; IV - promover a colonização; V - fiscalizar a aplicação das leis sociais; VI - difundir a instrução pública em todos os seus graus; VII - criar outros impostos, além dos que lhes são atribuídos privativamente." (Disponível em $<$

http://www.planalto.gov.br/ccivil 03/constituicao/constituicao34.htm> Acesso em 29 de junho de 2020 
todos em exercício conjunto e ordenado. Essa cooperação, conforme previsão do parágrafo único do art. 23, deve ser disciplinada por lei complementar que fixará "normas para a cooperação entre a União e os Estados, o Distrito Federal e os Municípios, tendo em vista o equilíbrio do desenvolvimento e do bem-estar em âmbito nacional".

No plano da saúde, essas competências são regulamentadas pela Lei Complementar 141/12, especialmente dedicada às regras de financiamento (regulamentando o art. 198), enquanto o SUS, por sua vez, é estruturado a nível infraconstitucional pelas Leis Federais 8.142/90 e 8.080/90, instituindo um modelo de prestação de saúde regionalizado e organizado segundo o critério da subsidiariedade.

No tocante à competência para legislar sobre proteção e defesa da saúde, o tratamento dado pela Constituição foi a de atribuí-la de forma concorrente entre os entes federativos (art. 24 , XII).

Nessa divisão da competência legislativa (ou normativa), cabe à União estabelecer normas gerais (não exaustivas, que traçam planos e estatuem mandados otimizadores) de saúde, havendo competência suplementar dos Estados (também dos municípios naquilo que couber, por força do art. 30, II). A lei de normas gerais funciona como uma moldura legislativa a ditar o espaço de preenchimento normativo das normas locais, que adaptarão a normatividade geral às peculiaridades de cada ente federado menor (HORTA, 2010, p. 323).

A atuação legislativa suplementar é um correlativo lógico da competência sobre normas gerais (principiológica) que a pressupõe (SILVA, 2000, p. 506), formando uma unidade cooperativa em matéria legislativa. Ressalte-se que, na falta completa de lei federal, podem os estados legislar amplamente, ficando suspensa a lei estadual com a superveniência da legislação federal $\left(\S^{0}\right)$.

A competência concorrente se baseia na ideia de coordenação - espécie de cooperação -, em que o exercício da competência é conjunto, mas com graus de participação diferenciados para cada ente federado, que pode atuar de forma autônoma. Na coordenação, "a decisão comum, tomada em escala federal, é adaptada e executada autonomamente por ente federado, adaptandoa às suas peculiaridades e necessidades" (BERCOVICI, 2002, p. 15).

Há nas competências concorrentes uma espécie de preempção da legislação federal, incumbida de dar à matéria uma certa uniformidade nacional sem que inviabilize a especificação de temas pela legislação suplementar dos entes menores. Os Estados, por sua vez, não podem fazer normas que contrariem a norma geral, sob pena de inconstitucionalidade por violação da regra constitucional de competência. 
No âmbito da saúde, para superar eventuais divergências na execução das competências material e legislativa, existem as chamadas Comissões de Pactuação, que definem esferas de atuação de cada ente. Trata-se da Comissão Intergestores Tripartite (União, Estados e Municípios) e da Comissão Intergestores Bipartite (Estados e Municípios).

No cenário da pandemia do COVID-19 teve o Supremo Tribunal Federal que decidir sobre o desenho da competência dos entes da federação no tocante à possibilidade de instituir medidas sanitárias de enfrentamento ao vírus. A Medida Provisória 926/2020 havia alterado dispositivos da Lei 13.979/20 e do Decreto 10.282/20, determinando, entre outras coisas, que “As medidas previstas (...), quando adotadas, deverão resguardar o exercício e o funcionamento de serviços públicos e atividades essenciais" (art. $3^{\circ}, \S 8^{\circ}$, da Lei 13.979/20), atividades estas sobre as quais, na nova redação da MP, "o Presidente da República disporá, mediante decreto" (art. $3^{\circ}, \S 9^{\circ}$, da Lei 13.979/20). O Partido Democrático Trabalhista (PDT) ajuizou a Ação Direta de Inconstitucionalidade 6341 contra essa MP argumentando violação à autonomia dos Estados e Municípios, além de promover uma redução do âmbito da competência comum sobre saúde, monopolizando-a nas mãos da União.

O STF, por maioria dos seus membros em inédita sessão realizada inteiramente por videoconferência no dia 15.04.2020, referendou a cautelar deferida pelo relator Min. Marco Aurélio. O tribunal adotou uma argumentação interessante, não declarando a inconstitucionalidade da MP, mas adotando interpretação conforme a Constituição para explicitar que apesar de o referido $\S 9^{\circ}$ atribuir ao Presidente da República a competência de dispor sobre os serviços e atividades essenciais, essa atribuição não excluiria a paralela atribuição de prefeitos e governadores que a exercem nos seus âmbitos federativos, até mesmo de forma mais restritiva se assim entenderem.

No seu voto, o relator argumentou que se por um lado a União pode sim estabelecer as normas gerais sobre saúde, inclusive aquelas sobre exercício da competência material, não pode por meio dessa normatização deixar de resguardar a atuação própria de cada ente no âmbito da sua esfera federativa, segundo a noção de competência material comum. Concordando com o relator, ponderou o Min. Fachinque a identificação da atribuição regulatória sobre determinado tema não pode premiar a inação do ente que se entende por competente, levando em conta que o entendimento pela ampliação da competência material para Estados e Municípios otimizaria a implementação das orientações da Organização Mundial de Saúde ${ }^{10}$.

${ }^{10}$ Decisões disponíveis em $<$ http://portal.stf.jus.br/processos/detalhe.asp?incidente=5880765 $>$ Acesso em 18 de junho de 2020 . 
Em suma, a decisão do Supremo Tribunal Federal na ADI 6341 referendou a validade dos decretos de governadores e prefeitos sobre a matéria, não estando subordinados às disposições normativas do Governo Federal. A consequência dessa decisão foi a de que, levando-se em conta a insistência do Governo Federal em abrir o comércio durante o auge da crise sanitária, pudessem os Governadores e Prefeitos, conforme as peculiaridades locais,ditar o rigor das medidas de isolamento seguindo as orientações da Organização Mundial de Saúde.

Percebe-se que, a despeito da tradição interpretativa centralizadora do Supremo Tribunal Federal em matéria de interpretação das cláusulas federativas, em se tratando de direito a saúde, a Corte reconheceu sua predominância regionalizada, sujeita às peculiaridades locais e respeitando-se a competência comum como meio de sua maior concretização.

Resta saber, contudo, qual a forma jurídica adequada para o estabelecimento das medidas sanitárias por Estados e Municípios. Isso porque tais providências, em cenários de calamidade, costumam envolver restrições de direitos.

\section{PRINCÍPIO DA LEGALIDADE}

É sabido que as recentes constituições passaram a contemplar, às explícitas, na enumeração dos direitos fundações que traçam, o direito à saúde. Disso não constituiu exceção a Constituição 1988, seja pela sua inserção no rol genérico do seu art. $6^{\circ}$, bem como e principalmente pela previsão do seu art. 196, a qual, no particular, apresenta uma densa similitude com o artigo 64 da Constituição da República Portuguesa ${ }^{11}$.

Examinando-se a doutrina, mais precisamente Gomes Canotilho (2007, p. 825), tem-se por visualizável no direito à proteção da saúde duas vertentes, sendo uma delas, a qual aqui mais nos interessa, a de laivo negativo, consistente em se exigir do Estado e de terceiros (particulares) que se abstenham de praticar qualquer ato que prejudique a saúde de outrem.

\footnotetext{
${ }^{11} 1$. Todos têm direito à proteção da saúde e o dever de a defender e promover. 2. O direito à proteção da saúde é realizado: a) Através de um serviço nacional de saúde universal e geral e, tendo em conta as condições económicas e sociais dos cidadãos, tendencialmente gratuito; b) Pela criação de condições económicas, sociais, culturais e ambientais que garantam, designadamente, a proteção da infância, da juventude e da velhice, e pela melhoria sistemática das condições de vida e de trabalho, bem como pela promoção da cultura física e desportiva, escolar e popular, e ainda pelo desenvolvimento da educação sanitária do povo e de práticas de vida saudável. 3. Para assegurar o direito à proteção da saúde, incumbe prioritariamente ao Estado: a) Garantir o acesso de todos os cidadãos, independentemente da sua condição económica, aos cuidados da medicina preventiva, curativa e de reabilitação; b) Garantir uma racional e eficiente cobertura de todo o país em recursos humanos e unidades de saúde; c) Orientar a sua ação para a socialização dos custos dos cuidados médicos e medicamentosos; d) Disciplinar e fiscalizar as formas empresariais e privadas da medicina, articulando-as com o serviço nacional de saúde, por forma a assegurar, nas instituições de saúde públicas e privadas, adequados padrões de eficiência e de qualidade; e) Disciplinar e controlar a produção, a distribuição, a comercialização e ouso dos produtos químicos, biológicos e farmacêuticos e outros meios de tratamento e diagnóstico; f) Estabelecer políticas de prevenção e tratamento da toxicodependência. 4. O serviço nacional de saúde tem gestão descentralizada e participada. Texto da VII Revisão Constitucional (2005) disponível em: www.parlamento.pt. Acesso em: 29 de junho de 2020.
} 
O mesmo parece ser explicitado por Tiago Viana Barra (2012, p. 422), muito embora parte de uma visão diferente das facetas positiva e negativa do direito em questão. Isso porque a vertente positiva, ao invés de dizer respeito ao aspecto de prestação estatal, representa a imposição de que o cidadão tenha um comportamento ativo de preservação da saúde, isto é, "o Estado impõe ao cidadão a obrigação de, por força da sua inserção na comunidade, tudo fazer para preservar o bom estado sanitário geral". Por outro lado, a negativa faculta ao cidadão exigir dos órgãos e entes públicos que se abstenham de práticas potencial ou atualmente lesivas da sua saúde.

A necessidade de fazer com que não se prejudique a saúde de terceiros enseja necessariamente a limitação da atividade dos sujeitos de direitos, efetuada em face de um interesse que se apresenta como pertencente à sociedade. Trata-se de interesse dito público que, assim, respalda, a edição de certas medidas restritivas, nas quais sobrelevam as balizas constitucionais.

Uma delas é a do respeito à legalidade, especialmente voltada à delimitação das espécies normativas que podem determiná-las ${ }^{12}$. O Supremo Tribunal Federal, em precedente elucidativo no $\mathrm{HC} 85060$ - $\mathrm{PR}^{13}$, rematou no sentido de que as intervenções em matéria de liberdade hão de exigir, inelutavelmente, lei formal, quando, de forma específica, houver previsão constitucional nesse sentido. Em assim não existindo, é possível restrição de direito mediante regulamento, expedido em face de remissão do legislador.

Duas hipóteses de reserva da lei formal são as inerentes à liberdade de iniciativa, à medida do art. 170, parágrafo único, da Lei Maior, e à imposição de sanções por infração administrativas, em virtude da incidência do art. 5, XXXIX, do mesmo diploma, à competência estatal sancionatória e não somente para as hipóteses de crimes ${ }^{14}$.

\footnotetext{
${ }^{12}$ Não esquecer que há diretrizes sobranceiras que devem ser respeitadas no que concerne ao conteúdo da disciplina normativa. É o caso da razoabilidade ou da obrigação de tratamento igualitário.

${ }^{13}$ Pleno, maioria, rel. Min. Eros Grau, DJe de 12-02-2009.

${ }^{14}$ No direito pátrio, por força expansiva da eficácia que é conatural aos direitos de defesa ou de primeira dimensão, prepondera no direito sancionador administrativo o princípio da legalidade, na forma da reserva da lei, tal qual se tem no domínio dos crimes ou delitos. A unidade do direito de punir do Estado atrai, grosso modo, a incidência dos direitos fundamentais numa perspectiva uniforme no campo punitivo. É de boa ordem advertir que não se presta para afirmar que o Supremo Tribunal Federal teria abandonado o princípio da legalidade estrita em sede de infrações administrativas o julgamento da ADI 3.330 (Plenário, maioria, rel. Min. Carlos Britto, julgado em 03-05-2012). A maneira mediante a qual se encontra redigida a ementa, bem como o item 43 do voto do relator, leva a um provável engano, o qual, a meu sentir, é amenizado pelo consignado no item 44 do referido pronunciamento. É que, no caso concreto, o art. $9^{\circ}$ da Lei 11.096/2005, um dos dispositivos desta inquinados de inconstitucionalidade, estatui que tanto a tipificação da infração quanto as sanções a serem manejadas pela Administração. O debate - e, com maior razão, a assertiva - somente se justificaria caso tais assuntos tivessem sido remetidos para o regulamento e, assim, tivesse sustentado a alegação do arguente. A questão da reserva legal em matéria de sanções administrativas - é preciso que não se esqueça - é de ser examinada de acordo com as peculiaridades do sistema jurídico. Por exemplo, no direito português, expõe Licínio Martins (2014) que a compreensão prevalecente é a de que o direito contra-ordenacional(ou direito de
} 
No que concerne à primeira hipótese, há a previsão da quarentena, nos termos do art. $2^{\circ}$, II, combinado com o art. $3^{\circ}$, II, da Lei 13.979/2020, esclarecendo-se, no $\S 8^{\circ}$ deste dispositivo, que o Presidente da república disporá sobre os serviços públicos e atividades essenciais.

Contudo, é de se notar que o legislador, diante da falibilidade que é conatural à ação humana, não consegue prever todas as situações de restrições que se evidenciem indispensáveis. Por exemplo, há que se notar a necessidade de fixação de limitações à propriedade, mais precisamente quanto a aspectos sanitários que digam respeito a residências, condomínios residenciais etc., tanto que a sua imposição, mesmo que não esteja sob a alçada da reserva legal, hão que ser impostas por regulamentos expedidos com amparo em lei.

Parcela relevante dessa legislação, por força das peculiaridades que envolvem, é de ser editada pelos Estados e Municípios.

No que concerne aos serviços públicos, cuja titularidade, por força da Constituição Federal, seja dos Estados, Distrito Federal e Municípios, é sabido competir a estes entes a edição da legislação inerente à sua disciplina.

Portanto, é preciso enfatizar que, nesse particular, não se afigura escorreita a aplicação do art. $3^{\circ}, \S 9^{\circ}$, da Lei $13.979 / 2020$. A matéria sobre a continuidade de sua prestação - e a forma para tanto - há que ser disciplinada por lei do ente federado.

E, como se não bastante, afigura-se importante saber se o nosso sistema jurídico se encontra apto para permitir o correto exercício da competência sancionatória. Isso porque se faz preciso saber se há lei prevendo, para os diversos segmentos da atividade fiscalizatória, principalmente para a exercício do âmbito de competência da União, a prática de infrações, sendo, desse modo, recomendável a adoção de tipos sancionadores em branco, a serem complementados por normas administrativas, porquanto são suscetíveis de reprimir a não observância de deveres e proibições com uma previsibilidade abrangente, prestando-se, assim, tanto para situações de normalidade quanto excepcionais.

mera ordenação social), é recusado o caráter de direito penal, muito embora se lhe reconheça como sendo direito sancionatório de âmbito punitivo. Isso, segundo o autor, faz com que se lhe confira uma conformação constitucional específica, em razão de se traduzir apenas na aplicação de coimas (multas) e não em privação de privação de liberdade, nem mesmo por conversão. Daí que o artigo $165^{\circ}$, alíneas $c$ e $d$, ao enumerar as matérias exclusivas do Parlamento, salvo autorização ao Governo para a edição de decreto-lei, reporta-se à definição de crimes, penas e medidas de segurança, mas que, quanto às infrações disciplinares e aos ilícitos de mera ordenação geral, restringe-se à delineação de seu regime geral. Não obstante, ao disciplinar medidas emergenciais quanto à COVID - 19, tipificando como infração administrativa punível com multa de 120 a 350 euros, o descumprimento da obrigatoriedade do uso de máscaras ou viseiras para o acesso ou permanência nos espaços e estabelecimentos comerciais e de prestação de serviços, nos serviços e edifícios de atendimento ao público e nos estabelecimentos de ensino e creches pelos funcionários docentes e não docentes e pelos alunos maiores de seis anos, laborou mediante a edição do Decreto-lei 20/2020 (art. $3^{\circ}$ ), acrescendo um artigo 13 - B ao Decreto-lei 10-A/2020. Aliás, este diploma, com o acréscimo de vários outros, traçaram disciplina minuciosa para os comportamentos sociais exigíveis durante o presente período de excepcionalidade. 
Daí que os entes federados devem se encontrar aparelhados com o manancial legislativo para o exercício do seu poder de polícia que diga respeito à físcalização sanitária, seja nas situações onde não prescindível a reserva legal, ou para respaldar a edição de regulamentos, os quais não dispensam a habilitação decorrente da precedência e primazia da lei. O Estado de Direito reclama que aquela competência assim se desenvolva.

\section{A LEGALIDADE NOS ESTADOS E MUNICÍPIOS}

Como visto nos tópicos anteriores, o princípio da legalidade é o condicionante jurídico do poder administrativo ordenador. Sabendo-se que Estados e Municípios, a exemplo da União, possuem competência para adotar medidas sanitárias (de polícia) no combate à pandemia, surge uma aparente oposição entre as amarras da legalidade e a premência da situação.

Nesse panorama, o que temos acompanhado é uma verdadeira erosão da legalidade justificada unicamente na urgência. Governadores e Prefeitos vêm, por meio de decreto, estabelecendo medidas ablatórias que entendem necessárias nesse momento de crise.

Por todos, é de ser considerado o exemplo do Estado da Paraíba que, por meio do Decreto $\mathrm{n}^{\mathrm{o}}$ 40.242, estabeleceu inúmeras medidas, entre elas a de suspensão de atividades comerciais e a obrigatoriedade do uso de máscaras pela população. Em um dos seus dispositivos, obriga qualquer estabelecimento, público ou privado, a só admitir a entrada em seu interior de pessoas usando máscaras, sob pena de multa de R\$100,00 (cemreais) por cada pessoa encontrada sem máscara no interior dos estabelecimentos ${ }^{15}$.

O mais curioso do caso paraibano não é apenas o fato de que se estabeleceu uma multa por meio de decreto, ignorando a legalidade, mas é que a Constituição do Estado da Paraíba ${ }^{16}$

\footnotetext{
${ }^{15}$ Art. $6^{\circ}$ Fica determinado que os estabelecimentos públicos e privados que estejam em funcionamento em todo o território estadual não permitam o acesso e a permanência no interior das suas dependências de pessoas que não estejam usando máscaras de proteção facial, que poderão ser de fabricação artesanal ou caseira. $\S 1^{\circ} \mathrm{O}$ descumprimento do disposto no caput deste artigo ensejará aplicação de multa de R\$100,00 (cem reais) por cada pessoa encontrada sem máscara no interior dos estabelecimentos, sem prejuízo da apuração de ilícitos criminais, decorrentes de infração à medida sanitária preventiva (art. 268 do CódigoPenal) e de desobediência (art. 330 do Código Penal). $\S 2^{\circ}$ Os recursos provenientes das multas aplicadas por descumprimento das normas deste decreto serão destinados às medidas de combate ao novo coronavírus (COVID-19).(Disponível em $<$ https://paraiba.pb.gov.br/noticias/joao-azevedo-assin-novo-decreto-ampliando-isolamento-comabrangencia-para-todosmunicipios/Decreton40.242Prorrogaisolamento15.05.20convertido.pdf $>$ Acesso em 19 de junho de 2020)

${ }^{16}$ Art. 61. O processo legislativo compreende a elaboração de: (...)V - medidas provisórias; (...)Art. 63. A iniciativa das leis complementares e ordinárias cabe a qualquer membro ou comissão da Assembleia Legislativa, ao Governador do Estado, ao Tribunal de Justiça, ao Procurador-Geral de Justiça e aos cidadãos, na forma e nos casos previstos nesta Constituição. $\S 3^{\circ}$ Em caso de relevância e urgência, o Governador do Estado poderá adotar medidas provisórias, com força de lei, devendo submetê-las de imediato à Assembleia Legislativa, que, estando em recesso, será convocada extraordinariamente para se reunir no prazo de cinco dias.(Disponível em $<$ http://www.al.pb.leg.br/wp-content/uploads/2017/02/Constitui\% $\%$ C3\%A7\%C3\%A30-
} 
adota a medida provisória como instrumento de elaboração do processo legislativo, instrumento este preterido em favor do decreto "executivo" para o estabelecimento de ordem de polícia e penalidade pecuniária.

Estados e Municípios tem a possibilidade de, espelhando a Constituição Federal, fazer uso de medidas provisórias desde que previstas pela respectiva Constituição Estadual e Lei Orgânica Municipal. É de se observar que a Constituição de 1967 , em seu art. $188^{17}$, proibia a edição do análogo decreto-lei em âmbito estadual, proibição que não se repetiu na Carta Cidadã de 1988 em relação às Medidas Provisórias ${ }^{18}$.

Apenas seis Estados preveem a atribuição de edição de medida provisória a seus Governadores: Santa Catarina, Acre, Tocantins, Maranhão, Paraíba e Piauí. Mesmo nesses Estados percebe-se que o instrumento é pouquíssimo utilizado por não ampliar substantivamente o poder de agenda do Executivo, o qual diante de competências limitadas prefere se valer de decretos ou projetos de lei com tramitação de urgência (RICCI; TOMIO, 2012).

Contudo, há de se observar que a medida provisória não é um caminho sempre acessível de by-pass ao processo legislativo pelo Poder Executivo; ela não se presta a possibilitar um cesarismo governamental. Como instrumento normativo previsto na constituição, sua disciplina comporta sensíveis restrições materiais que aqui nos interessam.

$\mathrm{O}$ art. $62, \S 1^{\circ}, \mathrm{I}, \mathrm{b}$, da Constituição Federal proíbe a edição de medida provisória sobre matéria de direito penal. Com esse limite, a Constituição apenas reconhece a centralidade do

Estadual-Atualizada-at\%C3\%A9-a-Emenda-40-de-2015.pdf $>$ Acesso em 19 de junho de 2020)

${ }^{17}$ Art 188 - Os Estados reformarão suas Constituições dentro em sessenta dias, para adaptá-las, no que couber, às normas desta Constituição. as quais, findo esse prazo, considerar-se-ão incorporadas automaticamente às cartas estaduais. Parágrafo único - As Constituições dos Estados poderão adotar o regime de leis delegadas, proibidos os decretos-leis. (Disponível em $<$ http://www.planalto.gov.br/ccivil_03/Constituicao/Constituicao67.htm > Acesso em 19 de junho de 2020)

${ }^{18}$ Roque AntonioCarrazza (2013, p. 305) argumenta que apesar de não haver uma admissão explícita às medidas provisórias estaduais e municipais na Constituição de 1988, o art. 25, §2º acaba por mencioná-las ao tratar da competência estadual para explorar o serviço de gás canalizado, proibindo nessa matéria a adoção de medidas provisórias. Nesse sentido, se a Constituição proíbe que o Estado edite medida provisória para regulamentar o serviço de gás, infere-se que esta é uma fonte ordinariamente editável por eles nas outras matérias de sua competência, o que se aplica, por extensão, também aos municípios. Tal entendimento é da substância da noção de autonomia dos entes federados, o que necessariamente deve se dar com paridade entre os entes federados, respeitado e desenho constitucional de suas atribuições. Também o Supremo Tribunal Federal já se debruçou sobre a temática na ADI 425-5/TO, de relatoria do Min. Maurício Corrêa, ajuizada pelo Partido do Movimento Democrático Brasileiro que buscava a invalidação de quatro medidas provisórias editadas pelo Governador do Estado de Tocantins. A Corte observou que, no caso, os atos normativos haviam sido editados em conformidade com o disposto na Constituição Estadual que previa, espelhando o constituinte federal, a medida provisória. Nessa esteira, observando-se o disposto no art. $25, \S 1^{\circ}$, da Constituição, entendeu o Tribunal que não se poderia vedar ao constituinte estadual aquilo que a Carta Magna não proibiu, aplicando-se no caso o princípio da simetria que se impõe em matéria de processo legislativo. Sendo assim, a decisão do STF foi no sentido de que é possível a previsão da medida provisória na Constituição Estadual, desde que observados os requisitos de relevância e urgência, dentre outras linhas básicas do modelo federal. Ressalte-se que tal a possibilidade de edição de medida provisória depende da previsão na Constituição do Estado e na Lei Orgânica Municipal, não podendo Governadores e Prefeitos se valerem diretamente da norma constitucional federal em analogia para tanto. 
princípio da legalidade no direito penal, considerando a máxima insculpida no art. $5^{\circ}$, XXXIX, de que não há crime sem lei que o defina nem penalidade sem prévia cominação legal. A mesma lógicaé válida em matéria de sanções administrativas (NOBRE JÚNIOR, 2000, p. 129), que, conforme visto em tópico anterior, demandam lei em sentido formal e específico para que sejam estabelecidas (reserva de lei em sentido estrito).

Outra solução destoaria do espírito do Estado de Direito que enfatiza a liberdade dos indivíduos em detrimento do poder punitivo do Administrador, de forma que o exercício do poder punitivo por parte do Estado não se compatibiliza com a discricionariedade própria da função administrativa. Mais especificamente, é preciso se observar a regra prevista no art. $5^{\circ}$, LIV, da Constituição ao dizer que ninguém será privado da liberdade ou de seus bens sem o devido processo legal, que aqui pode ser entendido como devido processo legislativo.

Mas a medida provisória não é o único instrumento constitucional capaz de evitar a morosidade do processo legislativo. A Constituição prevê diferentes regimes de tramitação de projetos de lei, dentre eles o regime de urgência, que dispensa de exigências, interstícios ou formalidades regimentais, possibilitando maior dinamicidade na produção legiferante.

Pontue-se que em âmbito estadual e municipal o procedimento de urgência ganha ainda mais agilidade pela quantidade significativamente inferior de parlamentares que compõem as Assembleias Legislativas e Câmaras de Vereadores.

A Constituição Federal, no seu art. 64, prevê expressamente o regime de urgência a pedido do Presidente da República para projetos de sua autoria. A previsão, contudo, não é excludente, sendo permitido que os regimentos internos das casas legislativas regulamentem outras hipóteses de instauração desse procedimento. Tomando o exemplo da Câmara dos Deputados, há um capítulo inteiro do seu regimento dedicado à disciplina da urgência, sendo uma das hipóteses de seu cabimento a tramitação de projeto de lei que trata de providências para atender a calamidade pública (art. 153, II).

No exemplo que demos da Paraíba, observamos que o regimento interno da Assembleia Legislativa disciplina o Regime de Urgência Urgentíssima ${ }^{19}$, que pode ser requerido para as

\footnotetext{
19،A Art. 157. Aprovado o requerimento de urgência urgentíssima, entrará a matéria em discussão e votação na mesma sessão, ocupando o primeiro lugar na Ordem do Dia, antes da pauta previamente organizada. $\S 1^{\circ} \mathrm{A}$ proposição submetida ao regime de urgência urgentíssima que não conte com os pareceres das comissões será designada pelo Presidente da Assembleia Legislativa, Relator Especial, para, na mesma sessão, apresentar parecer escrito ou oral. $\S 2^{\circ}$ Ao Relator Especial será concedido o prazo máximo de quinze minutos, prorrogável por igual tempo, a critério do Presidente em face da complexidade e extensão da proposição, para exarar seu parecer, devendo, o Presidente, se necessário, suspender a sessão para este fim. $\S 3^{\circ} \mathrm{Na}$ discussão e no encaminhamento da votação de proposição em regime de urgência urgentíssima, só o Autor, o Relator e Deputados inscritos poderão usar da palavra, e na metade do tempo previsto para as matérias em tramitação normal, alternando-se os oradores favoráveis e contrários, falando no máximo seis. $\S 4^{\circ}$ Encerrada a discussão com emendas, serão elas imediatamente apreciadas pelo Plenário, e o exame de constitucionalidade e
} 
proposições que versem sobre matérias de relevante e inadiável interesse estadual, com o objetivo de incluí-las automaticamente na Ordem do Dia para discussão e votação imediata, ainda que iniciada a sessão em que for apresentada (art. 155).

Assim, percebe-se que a mera urgência não pode servir de pretexto para suplantar as balizas do Estado de Direito e justificar a observância do devido processo legislativo. Tanto que também sobejam exemplos nos quais, na mesma circunstância de pandemia, se pôde observar o rápido desenrolar-se da deliberação legislativa para a confecção de leis que previssem medidas de polícia no combate à proliferação do vírus. Cite-se, como exemplo, a Lei Estadual 16.919/2020, de Pernambuco, a qual determina a adoção de medidas de proteção e enfrentamento ao COVID-19 nos condomínios do Estado de Pernambuco, prevendo sanção de multa entre mil e cinquenta mil reais para quem infringir suas determinações (art. $\left.9^{\circ}\right)^{20}$.

Não custa salientar que, na moldura do Estado constitucional de Direito, momentos de crise não têm o condão de criar governos ou ordenamentos de exceção que deturpem ou reformem seus fundamentos institucionais. O Estado constitucional permanece hígido mesmo durante situações de urgência, exigindo-se que todos os atos do governo se compatibilizem com seus princípios e regras constitucionais.

Mesmo diante das mais graves emergências, a reação legítima do Poder Público há que se fazer com respaldo e limite na própria normatividade constitucional. Mesmo diante de novas formas de organização, próprias das fórmulas constitucionalmente previstas, a Administração age em concretização da própria constituição e na medida de sua garantia, pois, como ensina Jorge Miranda (2012, p. 266), o brocardo saluspopuli suprema lex no Estado de Direito só é legítimo ao se valer das formas jurídicas próprias. Não existe, conclui o autor, duas Constituições - uma de crise e uma de normalidade -, a constituição é apenas uma, e eventuais suspensões que possam decorrer da necessidade são sempre parciais e específicas, mas assentes nos mesmos valores e princípios fundamentais que vigem na normalidade.

Nesse sentido, a crise não tem o condão de subverter a organização dos Poderes e os pilares funcionais sobre os quais se funda o Estado, mantendo-se imperativos, quando não expressamente excepcionados pela Constituição, os princípios democráticos e da legalidade, especialmente no caso das medidas mais sensíveis a direitos fundamentais.

juridicidade e da adequação financeira ou orçamentária e de mérito das emendas, será feito mediante parecer escrito ou oral apresentado diretamente em Plenário, sempre que possível pelos mesmos Relatores da proposição principal junto às Comissões que opinaram sobre a matéria, ou por Relator Especial designado pelo Presidente da Assembleia" Disponível em < http://www.al.pb.leg.br/wp-content/uploads/2013/07/RES-1.5782012-RIAL-atualizada-at\%C3\%A9-a-Resolu\%C3\%A7\%C3\%A3o-n\%C2\%BA-1.721-2017.pdf $>$ Acesso em 30 de junho de 2020

${ }^{20}$ Disponível em < https://www.legisweb.com.br/legislacao/?id=397166> Acesso em 30 de junho de 2020 
Assim, a urgência convive com o funcionamento regular dos Poderes e o ordenamento fornece mecanismos lícitos para que o Poder Público possa lidar agilmente com tal situação, sendo uma deles o procedimento legislativo específico para situações de gravidade que, por essa singularidade, reclamam soluções rápidas.

Prova insofismável disso é a de que, no estado de defesa, o art. 136, §1 ${ }^{\circ}$, da Constituição Federal, o decreto, o qual se submete ao beneplácito posterior do Parlamento, há que especificar as medidas coercitivas que vigorarão, devendo fazê-lo nos termos e nos limites da lei, sem prejuízo de outros limites fixados constitucionalmente. Mais gravoso, e, por isso, pressupondo autorização do Congresso Nacional, o estado de sítio, no caso de comoção grave de repercussão nacional ou fatos que denotem a ineficácia de medida tomada durante o estado de defesa, a vinculação jurídica de sua execução não é afastada, havendo o art. 139, I, da Lei Básica, enunciado as medidas restritivas cabíveis, as quais, igualmente, devem ser desenvolvidas com as cautelas legais respectivas. Em ambos os casos, não se exclui o controle jurisdicional em caso de lesão de direitos subjetivos, o que evidencia que a legalidade é imanente ao Estado de Direito, mesmo em situações emergenciais.

À derradeira, parece-nos alvissareiro que a crise pela qual passamos descortine nossa percepção à visualização de mecanismos que o ordenamento prevê para o enfrentamento de crises, em especial, nesse caso, os regimes de tramitação apropriados a garantir maior dinamicidade na deliberação de projetos de lei essenciais a estes propósitos, preservando, dessa forma, a vinculação do Estado à juridicidade.

\section{CONCLUSÃO}

Ultimas essas considerações, impõe concluir:

a) a situação de calamidade advinda com a pandemia do COVID - 19 exige da função administrativa a adoção de medidas restritivas de direitos, assomando como relevantes a harmonia destas com o Direito e a circunstância de que, no caso brasileiro, há que se considerar a natureza federativa do Estado;

b) o constituinte de 1988, seguindo o modelo da federação cooperativa, perfilhou, no que tange à tutela da saúde, a competência comum dos entes políticos, bem como, no plano da legislação, competência concorrente, em função da qual a União edita normas gerais, as quais podem ser complementadas por Estados, Distrito Federal e Municípios, consideradas as suas peculiaridades; 
c) o direito à saúde, consagrado pelo art. 196 da Lei Maior vigente, numa de suas perspectivas, impõe que ninguém - Poder Público ou particulares - exerça atividades que possam prejudicar a saúde alheia, o que legitima - máxime em períodos de calamidade - a tomada de medidas restritivas, as quais, conforme disciplina constitucional, hão de ser impostas mediante lei ou com base nesta;

d) as medidas tendentes à limitação de direitos, cuja maioria, por força da observância das necessidades locais, são de edição por Estados e Municípios, não podem prescindir de respaldo em lei, razão pela qual tais entes, pela via do procedimento legislativo abreviado, encontram-se obrigado a elaborar a legislação necessária, não podendo invocar, para tanto, o argumento de que a urgência, só por si, dispensa o respeito à legalidade tal como delineada pela constituição.

\section{REFERÊNCIAS}

AGRA, Walber de Moura. A política econômica como instrumento para realização da Constituição Econômica. Revista Forum de Direito Financeiro Econômico - RFDFE, Belo Horizonte, P. 161-184, 2019.

BARRA, Tiago Viana. Breves considerações sobre o Direito à Proteção da Saúde. O Direito, ano 144, II, 2012.

BERCOVICI, Gilberto. A descentralização de políticas sociais e o federalismo cooperativo brasileiro. Revista de Direito Sanitário, São Paulo, v. 3, n. 1, p. 13-28, mar. 2002.

CAETANO, Marcelo. Manual de direito administrativo. 10.ed. Coimbra: Livraria Almedina, 1990. t. 1.

CAMERON, David R. The expansion of the Public Economy: a comparative analysis. The American Political Science Review, v. 72, n. 4, dec. 1978.

CANOtilho, J. J. Gomes. Constituição da República Portuguesa Anotada. 4.ed. Coimbra: Coimbra Editora, 2007. v. 1.

CARAZZA, Roque Antonio. Curso de direito constitucional tributário. 29.ed.São Paulo: Malheiros, 2013.

CASTLES, Frank; MCKINLAY, Robert D. Does politics matter?European Journal of Political Research, v. 31,p. 99-107, 1979.

CAVALCANTI, Amaro. Regimen federativo: a RepublicaBrazileira. Rio de Janeiro: Imprensa Nacional, 1900.

HORTA, Raul Machado. Direito constitucional. 5. ed. Belo Horizonte: Del Rey, 2010. 
LOEWENSTEIN, Karl. Verfassungsrecht und Verfassungspraxis der Vereinigten Staaten. Berlin: Springer-Verlag, 1959.

MENDES, Gilmar Ferreira; BRANCO, Paulo Gustavo Gonet. Curso de Direito Constitucional. 12. ed. São Paulo: Saraiva, 2017.

MIRANDA. Jorge. Estado social, crise econômica e jurisdição constitucional. Revista da Faculdade de Direito da Universidade de Lisboa, v. 53, n. 1-2, p. 266, 2012.

NOBRE JÚNIOR, Edilson Pereira. Sanções administrativas e princípios de direito penal. Revista de Direito Administrativo, Rio de Janeiro, v. 219, p. 129, 2000.

OBINGER, Herbert. CASTLES, Francis; LEIBFRIED, Stephan. Introduction: federalism and the welfare state. In:Obinger, Herbert; Leibfried, Stephan; Castles, Francis (org.). Federalism and the welfare state: new world and european experiences. Cambridge: Cambridge University Press, 2005.

RICCI, Paolo; TOMIO, Fabricio. O poder da caneta: a Medida Provisória no processo legislativo estadual. Opinião Pública, Campinas , v. 18, n. 2, nov. 2012. Disponível em:https://www.scielo.br/scielo.php?script=sci_arttext\&pid=S0104-62762012000200001.

Acesso em: 19 jun. 2012

SILVA, José Afonso da. Curso de direito constitucional positivo. 19. ed. São Paulo: Malheiros, 2000. 